\title{
Role of differential and cell type-specific expression of cell cycle regulatory proteins in mediating progressive glomerular injury in human IgA nephropathy
}

\author{
Lian-Qun Qiu ${ }^{1}$, Raja Sinniah ${ }^{2}$ and Stephen I-H Hsu ${ }^{3,4}$ \\ ${ }^{1}$ Department of Pathology, Faculty of Medicine, the National University of Singapore, Singapore; \\ ${ }^{2}$ Department of Anatomical Pathology, Royal Perth Hospital, School of Surgery and Pathology, University of \\ Western Australia, Australia; ${ }^{3}$ Department of Medicine, Faculty of medicine, the National University of \\ Singapore, Singapore and ${ }^{4}$ Genome Institute of Singapore, Singapore
}

\begin{abstract}
The activities of cell cycle regulatory proteins have been reported to be associated with the development of pathological lesions in glomerulonephritis. To assess the cellular mechanisms underlying the mesangial cell proliferation and glomerulosclerosis in progressive human IgA nephropathy (IgAN), we examined the expression of E2F1, Rb, c-Myc, proliferating cell nuclear antigen (PCNA), cyclins (D1, E and A), cyclindependent kinase 2 (CDK2) and CDK inhibitors (p21 waf1, p27 ${ }^{\text {kip1 }}, 57^{\text {kip2 }}$ and p16 ${ }^{\text {inka }}$ ) by immunohistochemistry in renal biopsy specimens. Terminal deoxynucleotidyl transferase-mediated dUTP nick-end labeling (TUNEL) was also performed to detect the presence of apoptosis. In total, 51 cases of IgAN were categorized into four subgroups according to histological severity. A dramatic upregulation of E2F1 expression in mesangial cells was identified in proliferating glomeruli, which correlated well with the proliferation index. High endogenous expression of $\mathrm{p} 27^{\mathrm{kip} 1}$ and $\mathrm{p} 57^{\mathrm{kip} 2}$ by podocytes in normal glomeruli and glomeruli with minor lesions was observed to decrease in proliferating and sclerosing glomeruli; this pattern displayed a strong inverse correlation with the mean glomerulosclerosis score and the index of glomerular lesion. Increased apoptotic activity was identified in progressive glomerular lesions of advanced IgAN, which correlated with the proliferative activity in these lesions as assessed by total expression levels of PCNA and CDK2 in glomeruli, E2F1 expression levels in the mesangium, cyclin D1 expression levels in endothelium and the c-Myc glomerular staining score. Our results suggest that the onset and magnitude of mesangial cell proliferation and glomerulosclerosis is associated with the upregulation of E2F1 by mesangial cells and the downregulation of $\mathrm{p} 27^{\mathrm{kip} 1}$ and $\mathrm{p} 57^{\mathrm{kip} 2}$ by glomerular epithelial cells. The cell type-specific and coordinated regulation of proliferative and proapoptotic activities of cell cycle regulatory proteins may play an important role in mediating progressive glomerular injury in human IgAN.
\end{abstract}

Laboratory Investigation (2004) 84, 1112-1125, advance online publication, 21 June 2004; doi:10.1038/labinvest.3700144

Keywords: IgA nephropathy; cell cycle regulatory protein; mesangial cell proliferation; glomerulosclerosis; apoptosis

Cell cycle regulatory proteins (CCPs) govern not only cellular hypertrophy and proliferation, but also cellular apoptosis and differentiation. Mounting evidence has emerged that indicates a close link between cell cycle regulation and the development of histopathological lesions in glomerular diseases. ${ }^{1,2}$ In the experimental model of mesangial

Correspondence: Dr SI-H Hsu, MD, PhD, Department of Medicine, National University Hospital, 5 Lower Kent Ridge Road, Singapore 119074, Singapore.

E-mail: mdchsus@nus.edu.sg

Received 11 December 2003; revised 5 April 2004; accepted 6 May 2004; published online 21 June 2004 proliferative anti-Thy1.1 nephritis, increased expression of cyclins A, D1 and cyclin-dependent kinase 2 (CDK2) by mesangial cells in association with decreased high endogenous levels of CDK inhibitor (CKI) p27 ${ }^{\text {kip1 }}$ by glomerular epithelial cells (GECs), were required for mesangial cell proliferation. $^{3-5}$ The increased glomerular activity of CDK2 could be inhibited by the CDK antagonist roscovitine resulting in decreased cell proliferation and extracellular matrix production. ${ }^{6}$ In contrast, CKIs (p21 ${ }^{\text {waf1 }}$ and $\mathrm{p} 27^{\mathrm{kip} 1}$ ) were persistently increased in passive Heyman nephritis (PHN), a model of experimental membranous nephropathy, in which glomerular epithelial cells (GECs) are the target of 
complement-mediated injury. ${ }^{7}$ In cultured mesangial cells, expression of cyclins D1, E, A and CDK2 were increased upon stimulation with different mitogens, ${ }^{8-10}$ while proliferation of rat mesangial cells induced by platelet-derived growth factor was significantly inhibited by $\mathrm{p} 16^{\text {ink } 4}$ and moderately inhibited by $\mathrm{p} 21^{\text {waf. }}{ }^{4}$ These studies indicate that CCPs are differentially expressed in a cell typespecific manner that differs among various models of glomerular disease. CCPs are likely to play an important role in determining the glomerular response to injury.

IgA nephropathy (IgAN) is an immune-complexmediated glomerulonephritis characterized by mesangial cell proliferation and mesangial matrix expansion. ${ }^{11}$ Initially considered a benign disease, longitudinal follow-up studies have shown that IgAN is a slowly progressive disease with up to $50 \%$ of patients developing end-stage renal failure after several decades. ${ }^{12,13}$ Histopathological patterns of glomerular injury observed in IgAN vary from minimal change lesions through focal segmental glomerulonephritis to diffuse proliferative and sclerosing glomerulonephritis. ${ }^{14}$ Characterization of the role of cell cycle regulation in the pathogenesis of IgAN has been largely derived from in vitro studies and experimental animal models. In the current study of a series of human IgAN specimens obtained during diagnostic renal biopsy, we have attempted to investigate the differential expression of CCPs in three intrinsic glomerular cell types (mesangial cells, endothelial cells and glomerular epithelial cells), correlations between the cell type expression patterns of CCPs and various histopathological lesions, and the role of CCPs in mediating progressive glomerular injury in IgAN through their effects on glomerular cell proliferation, hypertrophy, apoptosis and differentiation.

\section{Materials and methods}

\section{Patients}

Tissue samples were obtained from 51 patients with IgAN (24 male and 27 female; mean age 38.3 years, range 15-70 years) during the period of 1997-2000, either by percutaneous renal biopsy at the National University Hospital of Singapore (NUH), or through referral from local nephrologists to the NUH pathology department for definitive diagnosis. Cases were selected on the basis of at least five glomeruli in the renal tissue, the availability of sufficient material, and the desire to obtain adequate pathological subtypes. Creatinine levels, creatinine clearance and magnitude of proteinuria based on 24-h urine collections at the time of diagnostic renal biopsy, were available for the majority of subjects. Biopsy specimens were processed for routine microscopic (hematoxylin and eosin (HE), periodic acid-schiff (PAS), Masson trichrome-silver impregnation (PAAG-MT) staining), electron microscopic and immunofluorescence analyses for the diagnosis of IgAN. ${ }^{15}$ Patients whose biopsy specimens stained prominently for IgA in the glomerular mesangial areas were selected after the exclusion of patients with systemic lupus erythematosus, HenöchSchonlein purpura, cirrhosis or other systemic diseases. IgAN cases were categorized into four subgroups according to the presence of progressively severe histological features on HE, PAS and PAAG-MT staining as previously described: ${ }^{16}$ (A) minor changes with mild thickening of the mesangium and no superimposed lesions $(N=5)$; (B) focal segmental proliferative/sclerosis with the majority of the uninvolved glomeruli showing minor changes $(N=21)$; (C) diffuse mesangial hypercellularity and hypertrophy, with focal superimposed lesions of sclerosis, adhesions or crescents in less than $40 \%$ of the glomeruli $(N=15)$; and (D) diffuse mesangial hypercellularity and hypertrophy, with more than $40 \%$ of the glomeruli showing superimposed lesions as in group $\mathrm{C}(N=10)$. In all, 10 renal samples without glomerular lesions obtained from nephrectomized specimens for renal carcinoma were used as normal controls.

Out of 51 IgAN subjects, 26 patients in the study were undergoing therapy of varying durations (from days to years, half of whom had received 1-2 months of therapy by the time of diagnostic renal biopsy). In all, 17 patients were receiving angiotensin-converting enzyme inhibitor (ACEI) or angiotensin II type 1 receptor blocker (AT1B) including Captopril, Enalapril, Ramipril, Lorsatan, etc (three, six, five, and three patients in subgroups A-D, respectively); five subjects were taking calcium channel blockers; and two patients from subgroups $\mathrm{B}$ and $\mathrm{C}$ each were receiving steroid treatment. Two subgroup D patients were undergoing hemodialysis; while the other two subjects with recurrent end-stage IgAN following renal transplantation were taking cyclosporin A and prednisolone or azathiopurine for immunosuppressive treatment.

For the sake of brevity, we have adopted the term 'progressive IgAN' in general throughout this study to denote the IgAN subgroups with 'progressively' severe glomerular lesions. Our use of this term is not intended to imply that the disease process always runs a natural history of progression from 'minimal' and 'focal segmental' lesions (subgroups A and B) to 'diffuse proliferative disease with varying degrees of sclerosis' lesions (subgroups C and D). Indeed, IgAN appears to be a heterogeneous disease characterized by diverse clinical manifestations and varied glomerular morphology at presentation, associated with different clinical outcomes. ${ }^{14,16}$

\section{Immunohistochemistry}

Paraformaldehyde-fixed paraffin-embedded tissue sections, $4 \mu \mathrm{m}$ thick, for both IgAN cases and normal 
controls were used in the study and a two-step immunostaining DAKO Envision $^{\mathrm{TM}}+$ System kit (Carpinteria, CA, USA) was employed for the immunohistochemistry. For double staining, an alkaline phosphatase (AP)-conjugated polymer (secondary antibody equivalent) was used in the first round of immunohistochemistry, while a horseradish peroxidase (HRP)-conjugated polymer was used for the second round of detection. Slides were subjected to microwave antigen retrieval with wetheat at $98^{\circ} \mathrm{C}$ for $10 \mathrm{~min}$ under $150 \mathrm{~W}$ (Micromed $\mathrm{T} / \mathrm{T}$, Milestone microwave system, Italy) prior to each round of immunohistochemistry (Table 1). Colorimetric detection was performed with nitroblue tetrazolium/5-bromo-4-chloro-3-indolyl phosphate (NBT/BCIP) for AP and 3,3'-diaminobenzidine tetrahydrochloride (DAB) for HRP. The specificity of labeling was confirmed by the absence of staining upon substitution of PBS or equal concentration of irrelevant nonimmune mouse serum for the primary antibody, or upon omission of secondary antibody. Tonsillar or breast carcinoma tissues served as positive controls.

\section{TdT-Mediated dUTP-Biotin Nick-End Labeling (TUNEL)}

TUNEL staining was performed as per the manufacturer's instructions using the In situ Cell Death Detection Kit, Peroxidase (Boehringer Mannheim, Germany). Positive and negative controls were established by DNase I digestion prior to the addition of TdT and omitting TdT, respectively. To avoid overestimation of apoptotic activity in TUNEL staining, only cells with observable morphological features of apoptosis were counted. Immunostaining for proliferating cell nuclear antigen (PCNA) was coupled to TUNEL staining, and the colorimetric detection was performed with Vector Blue (Vector Laboratories, Inc., Burlingame, CA, USA). Cells costained by TUNEL and PCNA appeared as green.

\section{Semiquantitative Histological Analysis}

Histological evaluation was performed under light microscopy by two independent pathologists who were blinded to the clinical and demographic characteristics of the patients, and to the prior pathologic categorization adopted in the study as well, as previously described. ${ }^{16}$ The glomerular positivity was expressed as the mean positive cell number per glomerular cross-section (GCS). A staining score was employed for analyzing c-Myc expression in glomeruli that took both intensity and extent of immunostaining into account. ${ }^{17,18}$ The staining score for each case was separately evaluated with respect to the intensity $(0-3+:$ negative, mild, moderate and marked staining) and extent $(0-4+$ : negative, $\leq 25, \leq 50, \leq 75$ and $>75 \%$ of involved glomeruli, respectively) of staining. The total staining score ranged from 0 (negative staining) to 7 (maximum staining intensity with $>75 \%$ of stained glomerular tufts).

The glomerular structures and cell components were identified morphologically by examining multiple sections with special stains, especially with the PAS stain. Only cells lying within the mesangium, along the inner walls of glomerular capillary loops and Bowman's capsule were defined as mesangial, endothelial and parietal epithelial cells, respectively. Cells attached to the outer aspect of the glomerular capillary walls were defined as visceral epithelial cells or podocytes. Owing to the scarcity of infiltrating leukocytes in the mesangium in IgA nephropathy, as corroborated by ultrastructural examination, ${ }^{14,19}$ we did not take this insignificant proportion of infiltrating cells into account, except for those immune cells that are found lying freely either in capillary lumina or Bowman's space.

The proliferation index (PI) was assessed as a measure of the degree of cellular proliferation in the mesangium, and expressed on an arbitrary scale $(0-3)$ based on the number of affected lobes: absent (0); mild, 1 lobe (1); moderate, 2-3 lobes (2); severe,

Table 1 List of antibodies used in the study

\begin{tabular}{|c|c|c|c|c|c|}
\hline Antibody & Source & Clone & Ig isotype & Dilution & $M W$ retrieval \\
\hline PCNA & DAKO & PC10 & $\operatorname{IgG} 2 \mathrm{a} / \kappa$ & $1: 600$ & TRS 6.0 \\
\hline Cyclin D1 & DAKO & DSC-6 & $\operatorname{IgG} 1 / \kappa$ & $1: 100$ & CA \\
\hline Cyclin E & Neomarker & CYE05 & $\mathrm{IgG} 2 \mathrm{a} / \kappa$ & $1: 20$ & CA \\
\hline Cyclin A & Neomarker & CYA06 & $\operatorname{IgG} 1 / \kappa$ & $1: 10$ & High pH \\
\hline CDK2 & Neomarker & 2B6 & IgG2b & $1: 50$ & High $\mathrm{pH}$ \\
\hline с-Мус & Neomarker & 9E10.3 & $\operatorname{IgG} 1 / \kappa$ & $1: 300$ & $\mathrm{CA}$ \\
\hline $\mathrm{E} 2 \mathrm{~F}-1$ & Neomarker & KH95 & $\operatorname{IgG} 2 a / \kappa$ & $1: 25$ & High pH \\
\hline $\mathrm{Rb}-1$ & Neomarker & $1 \mathrm{~F} 8$ & IgG1 & $1: 50$ & High $\mathrm{pH}$ \\
\hline P21 WAF1 & Neomarker & DCS-60.2 & IgG2a & $1: 25$ & High pH \\
\hline $\mathrm{p} 27^{\mathrm{Kip} 1}$ & Neomarker & DCS-72.F6 & IgG1 & $1: 200$ & TRS 6.0 \\
\hline p5 $7^{\text {Kip2 }}$ & Neomarker & 57P06 & $\mathrm{IgG} 2 \mathrm{~b} / \kappa$ & $1: 400$ & High pH \\
\hline $\mathrm{p} 16^{\text {ink4a }}$ & Neomarker & 16Р04 & $\operatorname{IgG} 1 / \lambda$ & $1: 100$ & High $\mathrm{pH}$ \\
\hline
\end{tabular}

${ }^{\mathrm{a}} \mathrm{MW}$ retrieval, microwave antigen-retrieval treatment; CA, $10 \mathrm{mM}$ citric acid; TRS 6.0, DAKO target-retrieval solution pH 6.0; high pH, DAKO target-retrieval solution high $\mathrm{pH}$. 
more than 4 lobes (3). The mean glomerulosclerosis score (GS score) was measured on a semiquantitative scale of 0-4 for the degree of glomerulosclerosis (0, no GS; 1 , $\leq 25 \% ; 2,26-50 \% ; 3,51-75 \%$; and 4, 76-100\% GS) per glomerulus and averaged as mean GS score per tissue section. ${ }^{20}$ The index of glomerular lesion (IGL) took into account both proliferative and sclerotic changes as previously described. ${ }^{21,22}$ In short, the degree of glomerular damage was graded 0-4 according to the percentage of injured lobules as the result of mesangial hypercellularity and glomerular sclerosis. The average of degrees for all glomeruli in one tissue section was calculated and registered as the IGL: $\left[\left(0 \times N_{0}\right)+\left(1 \times N_{1}\right)+\right.$ $\left.\left(2 \times N_{2}\right)+\left(3 \times N_{3}\right)+\left(4 \times N_{4}\right)\right] / N$, where $N_{0}-N_{4}=$ number of glomeruli showing changes of grades 0 to 4 , respectively, and $N=$ total glomeruli per tissue section. The validity of our 'descriptive' subgroup definitions was confirmed by the combined ability of these semiquantitative histologic indices to distinguish stage-specific pathologic features characteristic of each disease subgroup as demonstrated previously. ${ }^{16}$ Subgroups A and B differed from subgroups $\mathrm{C}$ and $\mathrm{D}$ by both the degree of proliferation and sclerosis, while subgroup C was distinguished from subgroup D by the extent of sclerotic lesions.

\section{Statistical Analysis}

All values were expressed as mean \pm s.e.m. Statistical significance was determined by one-way ANOVA, followed by Fisher's protected least significant difference post hoc analysis for multiple comparisons among four diseased subgroups and normal tissue. For non-parametric data, the MannWhitney $U$ and Wilcoxon rank-sum $W$-test were employed for multiple comparisons. Correlation was determined with Spearman's correlation coefficients. $P<0.05$ was considered significant.

\section{Results}

\section{Mesangial Overexpression of E2F1 in Progressive IgAN}

In this study, we did not detect baseline mesangial expression of cyclins E and D1 in normal samples, nor did we observe increased expression of CDK2, cyclin $\mathrm{A}, \mathrm{Rb}$ and PCNA in mesangial proliferative lesions as previously reported in in vitro studies, animal models, or proliferative forms of human glomerulonephritides. $^{3-5,8,10,23}$ In contrast, we detected a dramatic upregulation of E2F1 in mesangial cells in all IgAN subgroups, with the highest levels of $18.9 \pm 3.0$ positive mesangial cells per GCS in glomeruli of subgroup C (Figures $1 \mathrm{a}$ and $2 \mathrm{a}-\mathrm{c}$ ). This pattern correlated well with the proliferation index (PI), but not with the glomerulosclerosis score (GS score) and the index of glomerular lesion (IGL),
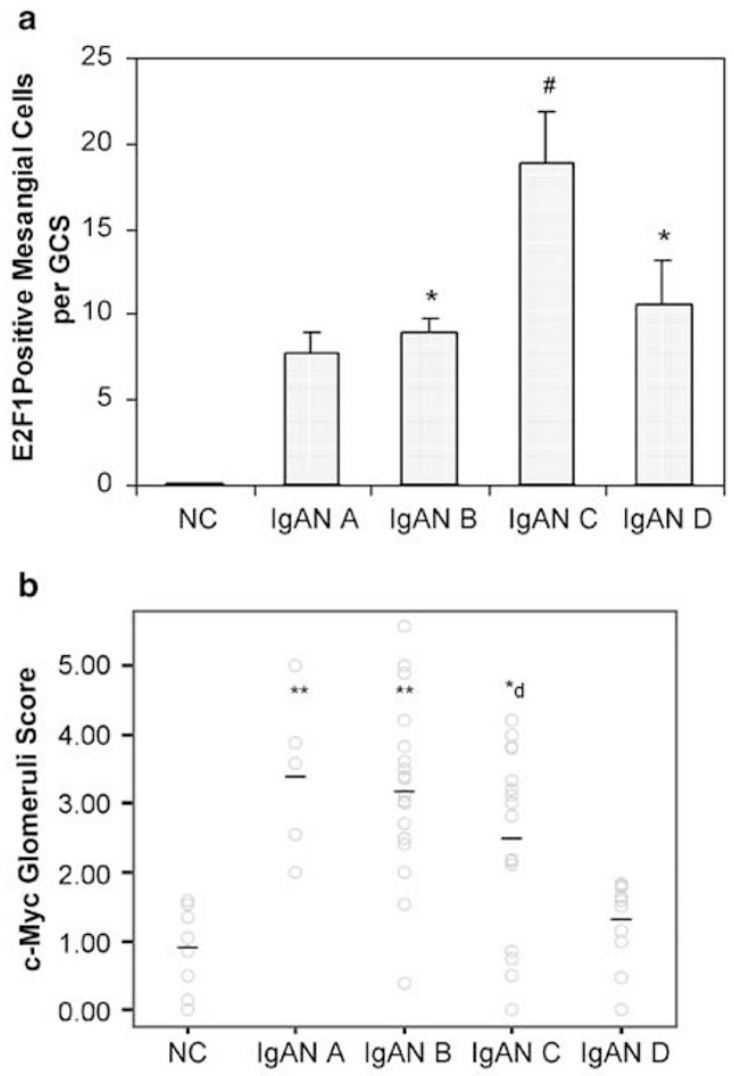

Figure 1 Upregulation of E2F1 expression in proliferative mesangial cells (a) and the c-Myc glomerular staining score in different subgroups of IgAN (b). GCS, glomerular cross-section. ${ }^{*} P<0.01$ vs NC; ${ }^{*} P<0.01$ vs NC and IgAN D; ${ }^{\mathrm{d}} P<0.05$ vs IgAN D; and ${ }^{\#} P<0.05$ vs all other subgroups.

suggesting a role for E2F1 overexpression in mediating mesangial cell proliferation. Notably, this upregulation of mesangial E2F1 was associated with the expression of cyclin A in mesangial cells, an increase in the c-Myc glomerular staining score as well as overexpression of cyclin D1 in endothelium (Table 2). We cannot exclude a role for E2F1 overexpression in sclerotic lesions, since we also observed the frequent expression of this marker in glomerulosclerosis present in subgroups C and D. Although c-Myc was predominantly expressed along the glomerular tufts (Figures $1 \mathrm{~b}$ and $2 \mathrm{~d}$, e), we observed c-Myc overexpression in expanded mesangium, where increased extracellular matrix (ECM) molecule accumulation was evident (Figure 2f).

\section{CCPs were Overexpressed by Glomerular Endothelium in Early Stages of IgAN}

Among the cell cycle markers examined, E2F1 and c-Myc expression were abundantly overexpressed along the glomerular tufts. Cyclin D1 and CDK2 were moderately overexpressed, while cyclin A and Rb were only modestly overexpressed by glomerular 

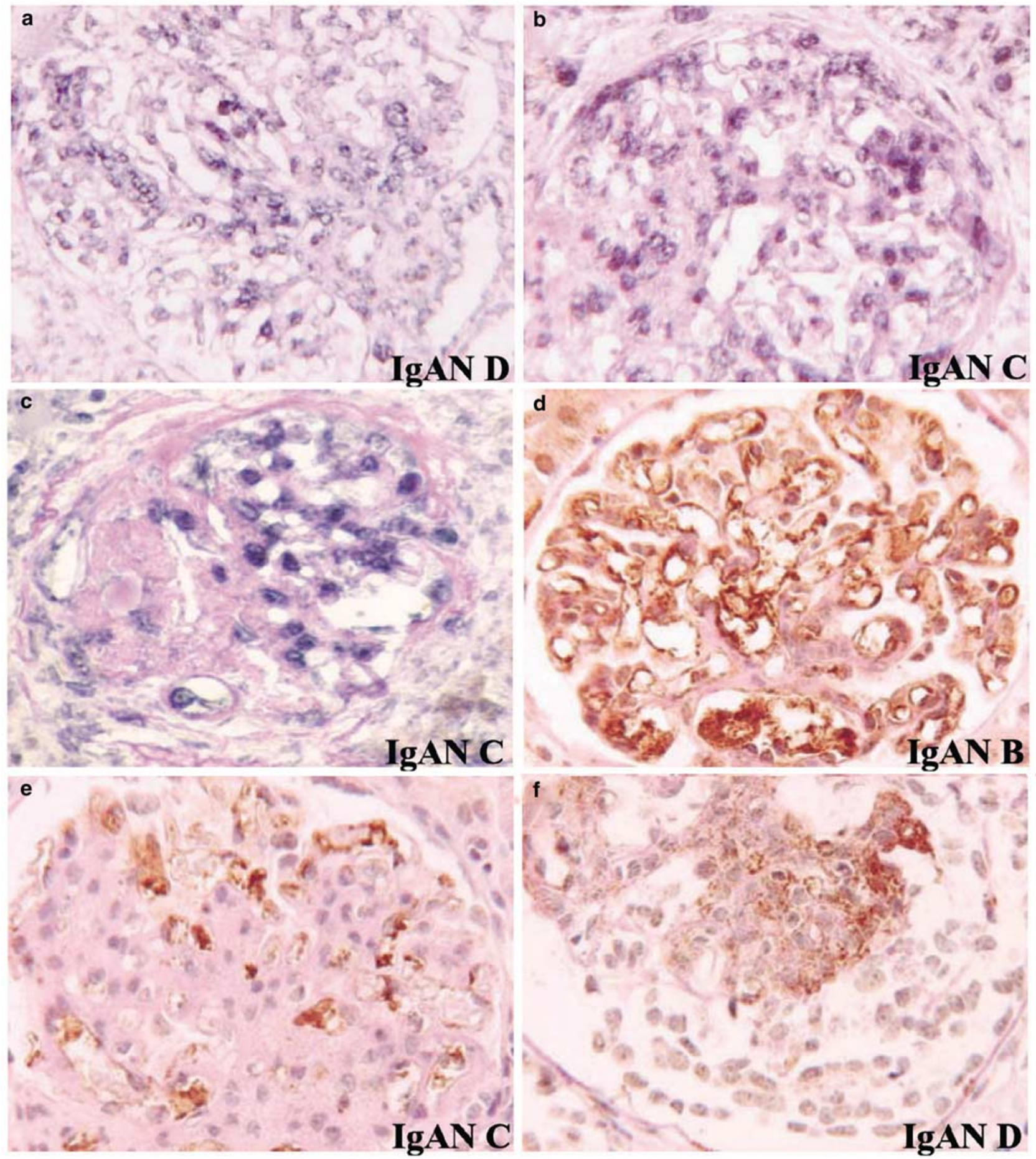

Figure 2 Immunohistochemical detection of E2F1 (purplish blue, a-c) and c-Myc (brown, d-f) overexpression in proliferating and sclerosing glomeruli of patients with IgAN. Mesangial overexpression of E2F1 was noted in glomeruli with marked segmental mesangial hypercellularity (a, b) and in a mildly proliferative glomerulus with 50\% glomerulosclerosis (c); counterstained with PAS. c-Myc immunoreactivity was evident along glomerular capillary loops in glomeruli with mild segmental glomerulonephritis (d), but not in glomeruli with marked global proliferation (e). There was nonspecific staining of proteinaceous material within the capillary lumina (d). Immunoreactive c-Myc in mesangium of a glomerulus was noted (f); counterstained with hematoxylin and PAS. Magnification: $\times 250(\mathbf{a})$ or $\times 400(\mathbf{b}-\mathbf{f})$.

endothelium (Figure 3). The increased expression of E2F1 and c-Myc was detected in mild IgAN (subgroup A), and persisted in advanced disease (subgroups B and C or D), while expression of cyclins D1 and A was increased in subgroups B and $\mathrm{C}$ but decreased in subgroup $\mathrm{D}$. With the exception 
Table 2 Mesangial expression of E2F1 is associated with G1 cyclin activity in glomeruli of IgAN ${ }^{\mathrm{a}}$

\begin{tabular}{lcc}
\hline & \multicolumn{2}{c}{ E2F1 in MC } \\
\cline { 2 - 3 } & Correlation coefficient & P-value \\
\hline Cyclin A (MC) & $0.358^{* *}$ & 0.007 \\
Rb (Glom) & 0.144 & 0.270 \\
c-Myc glomerular score & $0.387^{* *}$ & 0.003 \\
Cyclin D1 (Endo) & $0.357^{* *}$ & 0.006 \\
PCNA (Glom) & 0.091 & 0.515 \\
\hline
\end{tabular}

${ }^{\mathrm{a}}$ Correlation was evaluated with Spearman's correlation coffecients.

${ }^{* *}$ Correlation is significant at the 0.01 level (two-tailed).

Glom, glomeruli; MC, mesangial cells; Endo, endothelium cells; VEC,

visceral epithelial cells; PCNA, proliferating cell nuclear antigen. of $\mathrm{Rb}$ and $\mathrm{CDK} 2$, the endothelial expression of these cell cycle markers exhibited a statistically significant inverse correlation with the GS score and IGL (Table 3), or exhibited a trend towards inverse correlation with the IGL that did not reach statistical significance (E2F1).

\section{Expression of CKIs by Podocytes was Downregulated in Progressive IgAN}

Consistent with findings reported in anti-Thy1.1 experimental glomerulonephritis, ${ }^{3}$ we observed a downregulation of high endogenous $\mathrm{p} 27^{\mathrm{kip} 1}$ and p5 $7^{\text {kip2 }}$ by podocytes in progressively proliferating

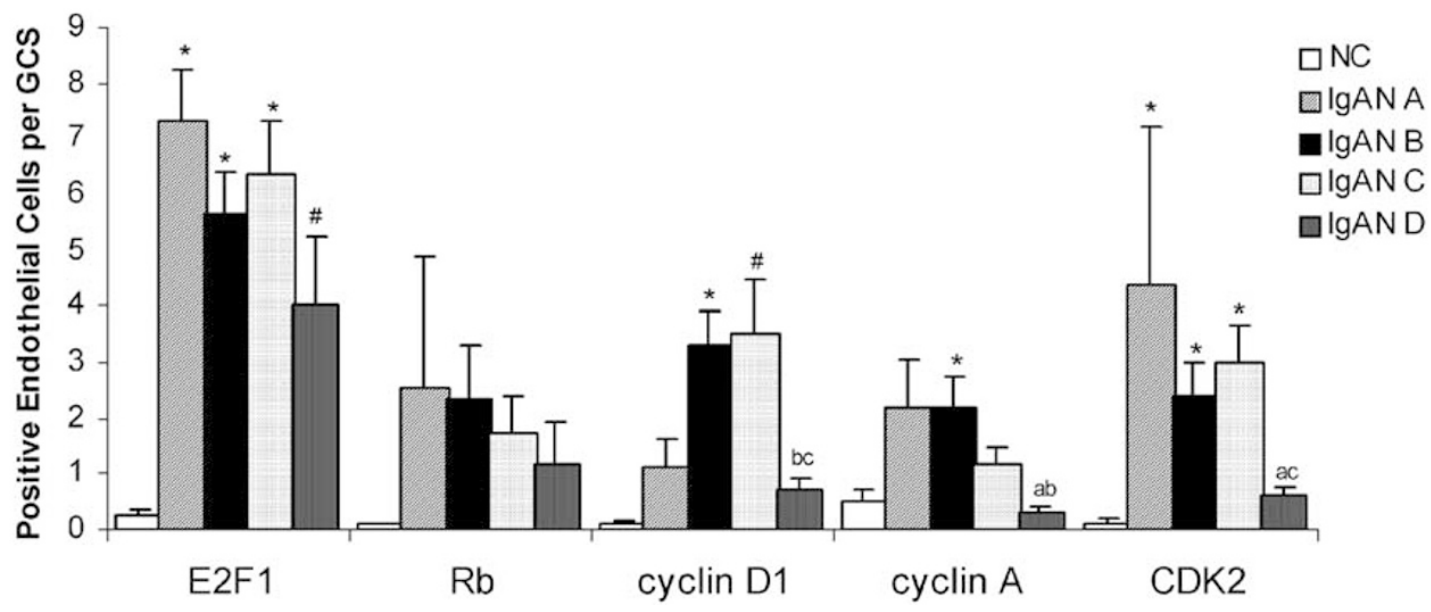

Figure 3 Early expression of cell cycle regulatory proteins by glomerular endothelium in the disease process of IgAN. ${ }^{*} P<0.001$ vs NC; ${ }^{\#} P<0.05$ vs NC; ${ }^{\text {abc }} P<0.05$ vs IgAN A-C.

Table 3 Correlation between expression of cell cycle regulatory proteins and histologic indices for the grade of proliferative and sclerotic lesions in progressive IgA nephropathy ${ }^{\mathrm{a}}$

\begin{tabular}{|c|c|c|c|c|c|c|}
\hline & \multicolumn{2}{|c|}{$P I$} & \multicolumn{2}{|c|}{$I G L$} & \multicolumn{2}{|c|}{ GS score } \\
\hline & $C C$ & $\mathrm{P}$-value & $C C$ & P-value & $C C$ & $\mathrm{P}$-value \\
\hline Cyclin A (MC) & 0.077 & 0.607 & -0.187 & 0.207 & -0.281 & 0.056 \\
\hline Cyclin A (Endo) & $-0.365^{*}$ & 0.012 & $-0.567^{* *}$ & $<0.001$ & $-0.499 * *$ & $<0.001$ \\
\hline E2F1 (MC) & $0.546^{* *}$ & $<0.001$ & 0.194 & 0.173 & 0.181 & 0.205 \\
\hline E2F1 (Endo) & 0.014 & 0.922 & -0.264 & 0.061 & -0.221 & 0.118 \\
\hline CDK2 (Glom) & 0.085 & 0.571 & -0.241 & 0.103 & -0.242 & 0.101 \\
\hline Rb (Glom) & 0.071 & 0.609 & -0.158 & 0.255 & -0.218 & 0.114 \\
\hline c-Myc Glomerular Score & -0.157 & 0.265 & $-0.571 * *$ & $<0.001$ & $-0.547 * *$ & $<0.001$ \\
\hline Cyclin D1 (Endo) & -0.069 & 0.631 & $-0.278^{*}$ & 0.048 & $-0.297^{*}$ & 0.034 \\
\hline p27 (VEC) & $-0.446^{* *}$ & 0.001 & -0.670 ** & $<0.001$ & $-0.630^{* *}$ & $<0.001$ \\
\hline p27 (MC) & 0.262 & 0.072 & 0.015 & 0.920 & -0.056 & 0.075 \\
\hline p21 (Glom) & 0.059 & 0.688 & $-0.286^{*}$ & 0.047 & $-0.300^{*}$ & 0.036 \\
\hline p57 (Glom) & -0.251 & 0.085 & $-0.615^{* *}$ & $<0.001$ & $-0.580^{* *}$ & $<0.001$ \\
\hline PCNA (Glom) & 0.248 & 0.086 & -0.002 & 0.988 & -0.020 & 0.893 \\
\hline
\end{tabular}

${ }^{\mathrm{a}}$ Correlation was evaluated with Spearman's correlation coefficients.

${ }^{*}$ Correlation is significant at the 0.05 level (two-tailed).

${ }^{* *}$ Correlation is significant at the 0.01 level (two-tailed).

CC, Spearman's rho correlation coefficient; PI, proliferation index; IGL, index of glomerular lesion; GS score, glomerulosclerosis score; other abbreviations as in Table 2. 
and sclerosing glomeruli of histologically severe IgAN (subgroups C and/or D, Figure 4). This pattern was inversely correlated with the GS score and IGL, and the PI for $\mathrm{p} 27^{\mathrm{kip} 1}$ (Table 3). Notably, p27 ${ }^{\mathrm{kip} 1}$ and p5 $7^{\text {kip2 }}$ immunoreactivity was frequently detected in hypertrophic podocytes in glomeruli with minor lesions, but not in hyperplastic epithelium within cellular lesions frequently observed in glomeruli with severe lesions (Figure 4g). The staining patterns for $\mathrm{p} 27^{\mathrm{kip} 1}$ and p57 $7^{\mathrm{kip} 2}$ were similar and localized to visceral epithelial cells (podocytes), while p2 $7^{\mathrm{kip} 1}$ expression was additionally detected in intraglomerular inflammatory cells as well as a few mesangial cells.

\section{Glomerular Epithelial Cell Expression of CCPs in Progressive IgAN}

In addition to the downregulation of CKIs in GECs, we readily detected the expression of PCNA, E2F1, $\mathrm{Rb}, \mathrm{c}-\mathrm{Myc}$, cyclin A, cyclin D1 and CDK2 in GECs in all four IgAN subgroups (Figure $5 \mathrm{~d}$ for PCNA epithelial immunoreactivity). Notably, the proliferative marker PCNA, which was expected to be overexpressed predominantly in proliferating mesangial cells, exhibited more frequent immunopositive staining of GECs in different IgAN subgroups. The total PCNA expression for all the cell types combined in diseased glomeruli did not exhibit significant change throughout the disease process (Figure 5a).

\section{Glomerular Cell Apoptosis and Proliferation were Strongly Correlated in Progressive IgAN}

Increased numbers of glomerular apoptotic cells were observed from subgroup A onwards and reached a peak level in subgroup $\mathrm{C}$, which correlated well with the PI, mean GS score and IGL ( $r=0.338-0.348$, respectively, $P<0.05)$, suggesting the involvement of apoptosis in both proliferative and sclerotic lesions (Figure 5a). The number of glomerular apoptotic cells decreased in subgroup D, which is characterized histologically by the presence of diffuse glomerular sclerosis/hyalinosis (Figure 5c, e).

Although glomerular cell apoptosis did not correlate with the expression of any CKIs examined, we observed a strong correlation between apoptotic and proliferative activity as assessed by total expression levels of PCNA and CDK2 in glomeruli, E2F1 expression levels in the mesangium, cyclin D1 expression levels in endothelium and the c-Myc glomerular staining score in subgroups A-C (Table 4). However, this correlation was not observed in subgroup D, in which persistent proliferation (as demonstrated by abundant expression of PCNA and E2F1) was associated with decreased apoptotic activity (Table 4).
CCPs were Differentially Expressed in Cellular Adhesions and Crescents

Cellular lesions including cellular adhesions and crescents are believed to be composed of proliferative parietal epithelial cells. ${ }^{24,25}$ In this study, we noted the overexpression of PCNA, c-Myc and E2F1 in addition to TUNEL positivity in these lesions, but no overexpression of the G1 cyclins, CDK2, or the CKIs p27 $7^{\mathrm{kip} 1}$ and $\mathrm{p} 57^{\mathrm{kip} 2}$. Notably, we observed overexpression of the CKIs $\mathrm{p} 21^{\text {wafi }}$ and $\mathrm{p} 16^{\text {ink4a }}$ in these lesions, and a similar staining pattern for p21 waf1 and PCNA in epithelial hyperplasia as demonstrated by staining of serial sections (Figure 6). PCNA, c-Myc and p21 waf1 overexpression was more closely associated with cellular crescents, while $\mathrm{p} 16^{\text {ink4a }}$ was differentially overexpressed in fibrocellular and fibrous crescents. In contrast, E2F1 and TUNEL positivity was demonstrated in both cellular and fibrous crescents.

\section{Correlation Analyses of CCP Expression with Clinical Indices of Poor Renal Prognosis}

Mesangial overexpression of E2F1 was positively correlated with the elevated level of serum creatinine at the time of biopsy $(r=0.501, P=0.001)$ in early to advanced stage disease (subgroups A-C). Downregulation of $\mathrm{p} 27^{\mathrm{kip} 1}$ and $\mathrm{p} 57^{\mathrm{kip} 2}$ by podocytes was inversely correlated with the deterioration of renal function as well as the magnitude of proteinuria at presentation in all four disease subgroups $(r=-0.443$ to $-0.638, P<0.01)$. We also observed positive correlations between cyclin A endothelium expression, c-Myc glomerular staining score, or CDK2 glomerular expression, and decline in the creatinine clearance rate $(r=0.370-0.451, P<0.05)$; such correlations were not observed with the magnitude of 24-h urine protein excretion.

\section{Discussion}

We report the results of the first systematic study to examine the role of differential and cell typespecific expression of CCPs in mediating progressive glomerular injury in human IgAN. Our results suggest that cell cycle regulation in glomerular intrinsic cells may underlie glomerular lesions from mesangial cell proliferation to glomerulosclerosis, leading to progressive deterioration of renal function.

We observed a predominant and dramatic upregulation of E2F1 in mesangium, which was linked with the grade of mesangial hypercellularity and the deterioration of renal function in advanced IgAN. This result differs significantly from those reported in anti-Thy1.1 model, in which CDK2 and cyclins A and D1 are predominantly overexpressed in mesangial cells. ${ }^{3-5}$ Recent progress has suggested that the regulation of E2F activity is mediated through the 
a
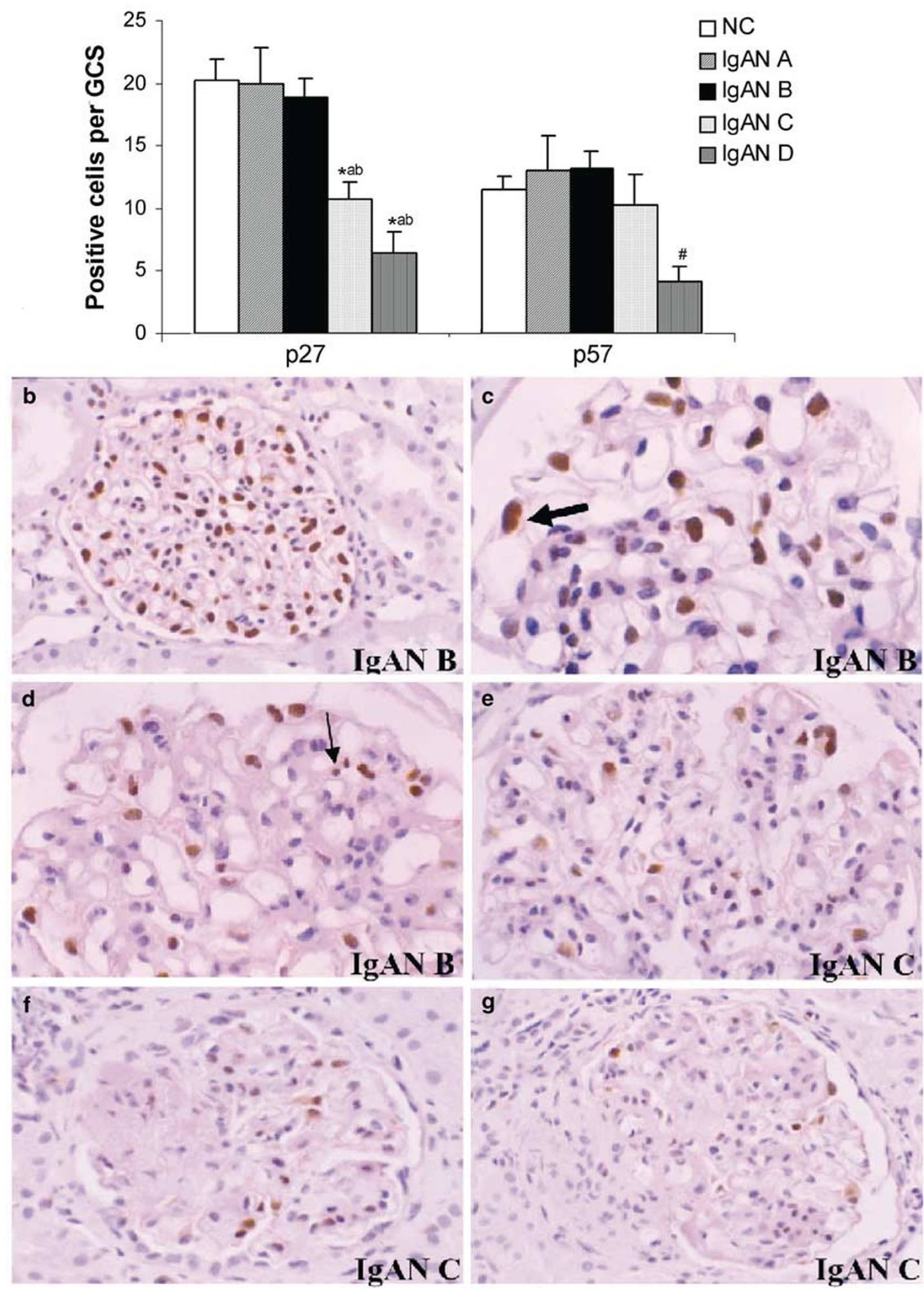

Figure 4 Expression of cyclin-dependent kinase inhibitors (p2 $7^{\mathrm{kip} 1}$ and $\mathrm{p} 57^{\mathrm{kip} 2}$ ) by podocytes in progressive glomerular injury. (a) High endogenous expression of $\mathrm{p} 27^{\mathrm{kip} 1}$ and $\mathrm{p} 57^{\mathrm{kip} 2}$ by podocytes decreased with progressive glomerular injury $\left({ }^{*} P<0.05 \mathrm{Vs} \mathrm{NC}\right.$; ${ }^{\text {ab }} P<0.05 \mathrm{VS}$ IgAN A and B; ${ }^{*} P<0.05$ vs all other groups). Photomicrographs showing high levels of p2 $7^{\text {kip } 1}$ expressed by podocytes (brown) in normal glomeruli and glomeruli with mild lesions (b, c), which were gradually decreased in glomeruli with moderate proliferation (d, e) and glomerulosclerosis (f), and further decreased in marked global proliferative and sclerotic glomeruli (g); immunoreactive p27 ${ }^{\text {kip1 }}$ was absent in cellular crescents (position 6 to 9 o'clock in g). Overexpression of p27 $7^{\text {kip } 1}$ by podocytes was also noted in two small nuclei side by side (d, thin arrow), likely podocyte daughter cells; as well as in hypertrophic podocytes (c, thick arrow). Counterstained with hematoxylin and PAS. Magnification: $\times 400$. 

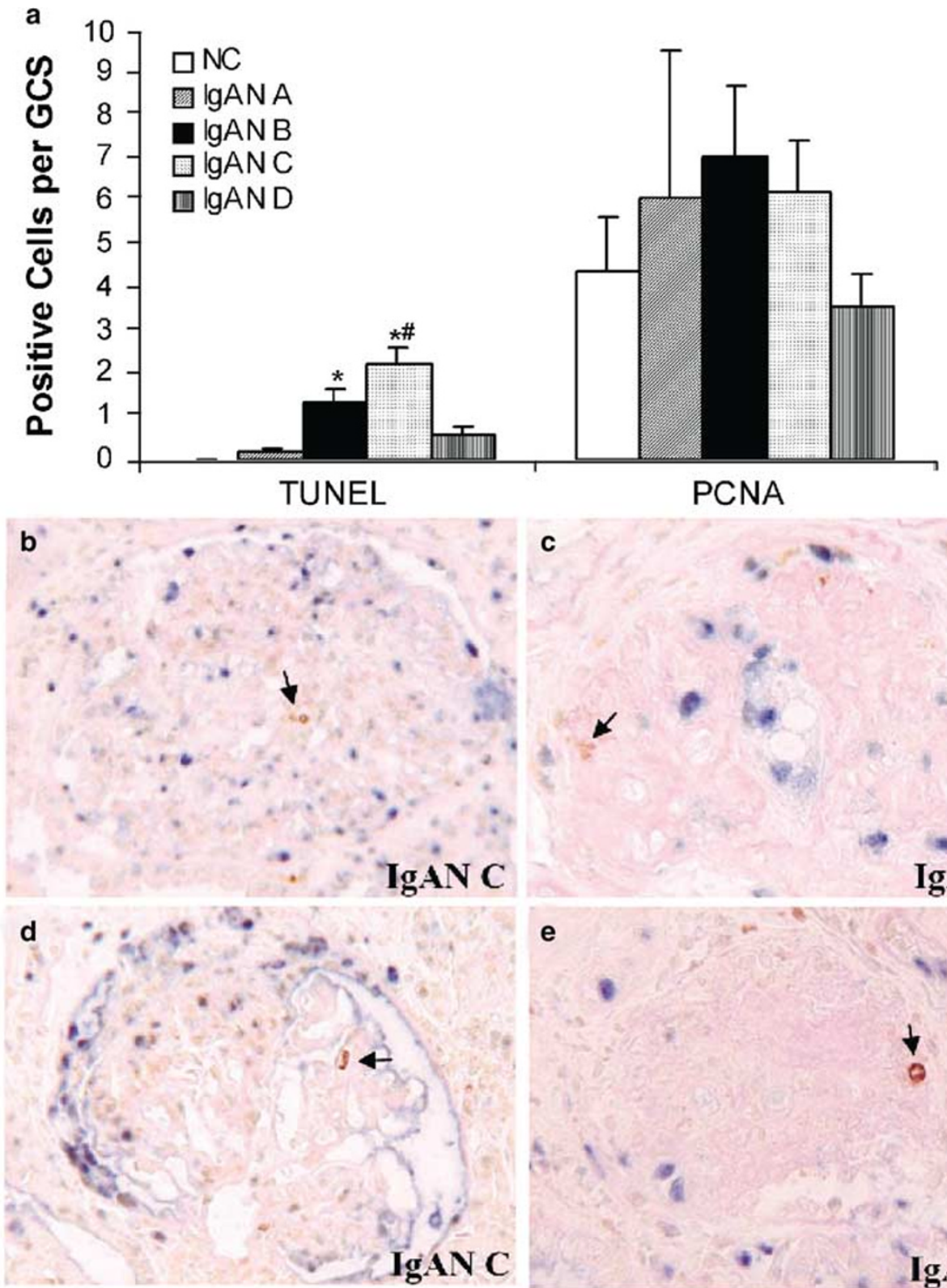

c
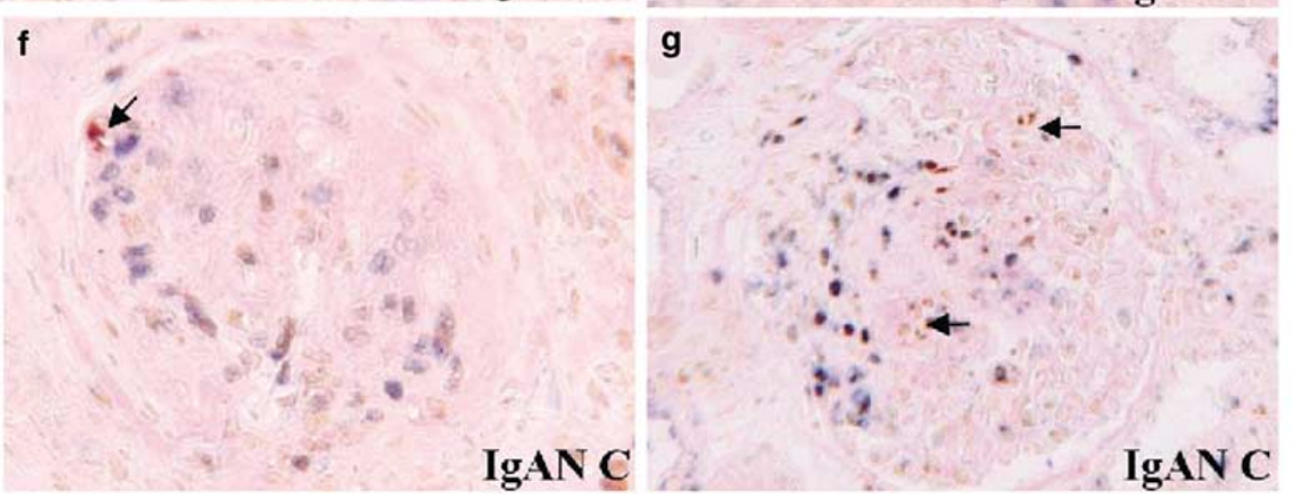

Figure 5 Evaluation of apoptotic and proliferative activities by TUNEL (brown) and PCNA (blue) double staining. (a) Analysis of TUNEL and PCNA positivity at different stages of IgAN ( ${ }^{*} P<0.05$ vs NC; ${ }^{*} P<0.05$ vs IgAN A and D). TUNEL positive cells with morphologic changes (arrows) were identified in the mesangium (b, g), endothelium (d), and sclerotic region (c, e) of glomeruli at advanced (b, d, f, g) and end disease (c, e) stages. Nuclear shrinkage, nuclear chromatin condensation (d-f), and nuclear fragmentation (b, $\mathbf{c}, \mathbf{g})$ were evident. Counterstained with PAS. Magnification: $\times 400$. 
Table 4 Correlation between apoptotic and proliferative activity at different IgAN disease stages ${ }^{\mathrm{a}}$

\begin{tabular}{llcr}
\hline \multirow{2}{*}{$\begin{array}{l}\text { Disease } \\
\text { stage }\end{array}$} & \multirow{2}{*}{ Marker } & \multicolumn{2}{c}{ Total TUNEL in glomeruli } \\
\cline { 3 - 4 } & & $\begin{array}{c}\text { Correlation } \\
\text { coefficient }\end{array}$ & P-value \\
\hline IgAN A-C & PCNA (Glom) & $0.321^{*}$ & \\
& E2F1 (MC) & $0.486^{* *}$ & $<0.014$ \\
& CDK2 (Glom) & $0.411^{* *}$ & 0.001 \\
& Rb (Glom) & $0.268^{*}$ & 0.050 \\
& c-Myc glomerular & $0.353^{* *}$ & 0.008 \\
& score & & \\
& cyclin D1 (Endo) & $0.367^{* *}$ & 0.007 \\
& p27 (VEC) & -0.227 & 0.110 \\
& p27 (MC) & 0.264 & 0.061 \\
p57 (Glom) & -0.132 & 0.350 \\
p21 (Glom) & 0.175 & 0.214 \\
IgAN D & PCNA (Glom) & 0.116 & 0.751 \\
& E2F1 (MC) & -0.072 & 0.866 \\
CDK2 (Glom) & -0.277 & 0.470 \\
& Rb (Glom) & -0.428 & 0.250 \\
c-Myc Glomerular & -0.116 & 0.750 \\
Score & & \\
& cyclin D1 (Endo) & -0.535 & 0.111 \\
\hline
\end{tabular}

${ }^{\mathrm{a} C o r r e l a t i o n}$ was evaluated with Spearman's correlation coefficients in early- to advanced-stage disease (subgroups A-C) and end-stage disease (subgroup D), respectively.

${ }^{*}$ Correlation is significant at the 0.05 level (two-tailed)

**Correlation is significant at the 0.01 level (two-tailed).

Abbreviations as in Table 2 .

induction, phosphorylation and/or localization of E2Fs, in addition to the phosphorylation status of $\mathrm{Rb}^{26}$ A 20-fold increase of E2F1 protein during the G1/S phase transition was observed in activated rat mesangial cells. ${ }^{27}$ The mesangial upregulation of E2F1 observed in progressive glomerular injury in this study may reflect both elevated E2F1 protein levels as well as increased E2F1 activity.

Acting as a key modulator of the G1/S phase transition, E2F1 controls the expression of multiple genes involved in regulation of all phases of cell cycle progression, including $c-m y c, P C N A$, cyclin $A$ and $C D K 2 .{ }^{28,29}$ In vitro, overexpression of E2F1 could promote mesangial cell proliferation and increase the expression of G1 cyclins including cyclins D1, E and A. ${ }^{27,30}$ E2F decoy oligonucleotides have been shown to be capable of suppressing mesangial cell proliferation in vitro and in vivo. ${ }^{31,32}$ ECM-induced cell cycle arrest in mesangial cells was shown to be associated with transcriptional repression of E2F-responsive genes such as c-myc, cyclin $A$ and $c d c 2 .{ }^{33}$ In contrast to these reports, we did not detect a corresponding upregulation of the protein products of E2F-responsive genes in the mesangium of glomeruli in human IgAN. This may be due, at least in part, to the very short half-lives $(<30-60 \mathrm{~min})$ or susceptibility to protein degradation of various cyclins and CDKs, thus limiting our ability to detect the expression of such molecules in human renal biopsy specimens. Alternatively, the conflicting results observed in our study as compared to the published literature may reflect true differences between the in vivo expression of these proteins in human IgAN as compared to in vitro and animal model systems. Nonetheless, our findings of increased c-Myc expression in thickened mesangium, as well as the strong correlation between the upregulation of E2F1 in mesangial cells and the G1 cyclins in various glomerular cell types, support our hypothesis that E2F1 mesangial activity may play a central role in the mesangial proliferative response to glomerular injury in human IgAN.

Similar to the findings in the anti-Thy1.1 model, ${ }^{3}$ we have also demonstrated a close relationship between mesangial cell proliferation and decreased levels of $\mathrm{p} 27^{\mathrm{kip} 1}$ and $\mathrm{p} 57^{\mathrm{kip} 2}$ by podocytes in human IgAN. The downregulation of high endogenous $\mathrm{p} 27^{\mathrm{kip} 1}$ and $\mathrm{p} 57^{\mathrm{kip} 2}$ in GECs is not only associated with the onset of mesangial proliferation, but is also linked with the grade of glomerular lesions including mesangial hypercellularity and glomerulosclerosis, consistent with the observed inverse correlation with the progression rate of renal dysfunction. ${ }^{16}$ In p2 $7^{\text {kip1 }}$ knockout mice, the absence of p2 $7^{\text {kip } 1}$ has been associated with a marked increase in the severity of the glomerular response to injury in the antiglomerular basement membrane model of crescentic glomerulonephritis (anti-GBM GN). ${ }^{34}$ These studies strongly suggest that $\mathrm{p} 27^{\mathrm{kip} 1}$ and $\mathrm{p} 57^{\mathrm{kip} 2}$ function physiologically to inhibit cellular proliferation, and that their downregulation is necessary for the development of proliferative and sclerotic damage in progressive glomerulonephritis.

In normal glomeruli, only $1-2 \%$ of glomerular endothelial cells, and to a much lesser extent, mesangial cells, actively proliferate, whereas podocytes do not, as determined by labeling murine glomerular cells with $\left[{ }^{3} \mathrm{H}\right]$ thymidine, a marker of DNA synthesis. ${ }^{35}$ In the present study, the dramatic upregulation of CCPs observed in glomerular endothelium of human IgAN biopsy specimens suggests a substantially increased turn-over rate of glomerular endothelial cells in addition to mesangial cell proliferation. The increase in CDK2 expression by glomerular endothelium observed in IgAN together with the increased CDK2 expression during mesangial cell proliferation reported in anti-Thy1.1 nephritis, ${ }^{3}$ support the notion that the in vivo expression of certain cell cycle proteins may differ from that described in nonrenal cells studied in vitro. Accelerated cell cycle progression in glomerular endothelium may sensitize these cells to various stimuli such as inflammatory and apoptotic stimuli. The overexpression of CCPs in glomerular endothelium may thus antecede and underlie the progressive glomerular damage observed later in advanced- and end-stage IgAN.

We suggest that the phenotypic dysregulation and proliferation observed in GECs, which are hallmarks of progressive glomerulonephritis, may be determined, at least in part, by CCPs. The notable high 

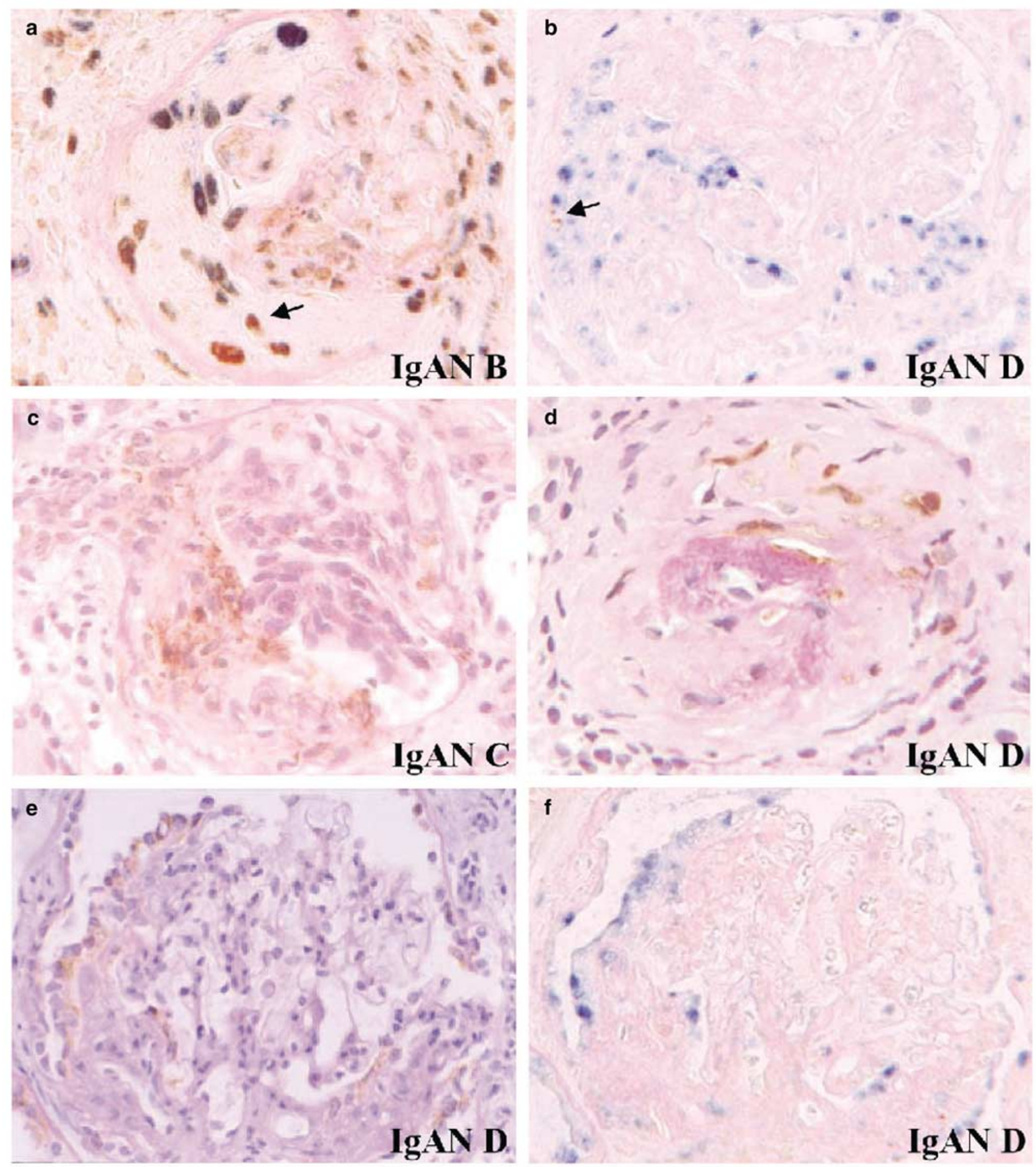

Figure 6 Expression of cell cycle regulatory proteins in cellular lesions in progressive IgAN. Both PCNA (blue) and TUNEL (brown, arrows) staining were observed in a cellular adhesion (b) and fibrocellular crescent (a). c-Myc (c, brown) and p16 ${ }^{\text {ink4a }}$ (d, brown) overexpression were noted in a cellular crescent and fibrocellular crescent, respectively. Immunohistochemical detection of p21 ${ }^{\text {waf1 }}$ (e, brown) and PCNA (f, blue) expression on serial sections demonstrated a similar staining pattern for PCNA and p21 ${ }^{\text {waf1 }}$ in glomerular epithelial hyperplasia. (a), (b) and (f) counterstained with PAS only; (c-e) counterstained with both hematoxylin and PAS. Magnification: $\times 400$.

levels of $\mathrm{p} 27^{\mathrm{kip} 1}$ and $\mathrm{p} 57^{\mathrm{kip} 2}$ expression by podocytes in normal glomeruli and glomeruli exhibiting mild lesions were associated with podocyte hypertrophy (Figure 4c), likely reflecting G1 phase arrest. In contrast, downregulation of $\mathrm{p} 27^{\mathrm{kip} 1}$ and $\mathrm{p} 57^{\mathrm{kip} 2}$ expression in glomeruli with histologically severe features, together with the overexpression of G1-, S-, and G2-phase associated CCPs in GECs, may confer 
GEC transdifferentiation/dedifferentiation potential, leading to epithelial hyperplasia. Many studies have suggested that epithelial hyperplasia in various glomerular diseases is characterized by cells that stain negatively for podocyte markers (eg synaptopodin and PHM-5) and CKIs, stain positively for cytokeratin, and occasionally stain positively for CDK2, Ki-67 and cyclins (E, A, B1)..$^{7,25,36-38}$ We now provide evidence of PCNA, c-Myc and E2F1 overexpression in these lesions against a background of absent $\mathrm{p} 27^{\mathrm{kip} 1}$ and p $57^{\mathrm{kip} 2}$ expression in IgAN. Novel findings included a weak to moderate expression of p21 $1^{\text {waf1 }}$ and $\mathrm{p} 16^{\text {ink4a }}$ in these cellular lesions, in addition to the colocalization of p21 wafi with PCNA in these epithelial lesions. The carboxyl terminus of p21 waf1 contains the PCNA-interacting domain, which provides a 'framework' for the assembly of cyclins, CDKs, and PCNA required for DNA synthesis. $^{2,4}$ p21 $2{ }^{\text {waf1 }}$ may thus function in the regulation of a G1/S-phase check-point, rather than as an antiproliferative signal, an inducer of withdrawal from the cell cycle or a promoter of terminal differentiation.

Apoptosis has been implicated as a cell deletion mechanism for removal of excess mesangial cells, endothelial cells and GECs during progressive glomerulosclerosis in many experimental models. ${ }^{39-41}$ Apoptosis may serve to prevent the propagation of damaged DNA to daughter cells. In our study of human IgAN, we have demonstrated increased apoptotic activity in glomeruli in advanced-stage disease (subgroup C), which is highly correlated with the overexpression of pro-proliferative CCPs. Increased glomerular cell apoptosis (death) and proliferation (growth) may be coordinately regulated if increased proliferation in diseased glomeruli generates more cells that can enter the apoptotic pathway, and/or if it induces an active compensatory proapoptotic response that serves to counterbalance cellular hyperplasia. The potential apoptotic pathway in diseased glomeruli could be associated with the increased activity of E2F1 and c-Myc, which may sensitize the intrinsic glomerular cells to apoptotic stimuli. However, the balance between apoptosis and proliferation appears to be perturbed when proliferation occurs in the setting of decreased apoptotic activity as observed in endstage disease, leading to irreversible glomerular damage. The excess apoptosis observed in subgroup $\mathrm{C}$ in relation to the diffuse global sclerosis and/or severe glomerulosclerosis observed in subgroup D, suggests that apoptosis-mediated hypocellularity may contribute to the development of glomerular sclerotic lesions in IgAN as well. In other studies of IgAN, increased glomerular apoptosis has been reported to be associated with the level of proteinuria, ${ }^{42}$ the degree of glomerulosclerosis and the deterioration of renal function. ${ }^{43}$

A major aim of our study is to identify a clinically relevant surrogate marker for the glomerular lesions associated with progressive IgAN. Candidate pro- liferation markers for mesangial hypercellularity have been previously proposed, including cyclin A, cyclin D1, E2F-1, c-Myc, PCNA or Ki-67, and CKIs. ${ }^{44}$ In anti-Thy1.1 model of mesangioproliferative glomerulonephritis, immunohistochemical detection clearly demonstrated an increase in the number of PCNA expressing cells on day $5 .{ }^{5}$ Comparable results were reported in mice with Habu toxin glomerulopathy. ${ }^{44}$ In cultured mesangial cells, proliferation could be inhibited by using antisense oligonucleotides against cell cycle-associated proteins such as PCNA or Ki-67. ${ }^{45}$ However, our findings in progressive IgAN suggest that PCNA may not be a reliable marker of mesangial hypercellularity. This was in agreement with an early observation in human proliferative glomerulonephritis including IgAN. ${ }^{23}$ Firstly, PCNA has been reported to be expressed in TUNEL-positive cells, ${ }^{41}$ consistent with our findings. Thus, PCNA immunopositive cells are not necessarily committed to cell division, but may also undergo apoptosis. Secondly, PCNA positivity is not limited to mesangial cells, but also found in endothelial cells and GECs as shown in our study; and the total PCNA expression for all the cell types combined remained unchallenged in progressive glomerular injury. We propose that E2F1 may be a more reliable and clinically relevant surrogate marker than PCNA for the glomerular lesions associated with progressive IgAN, such as mesangial hypercellularity, glomerulosclerosis and glomerular cell apoptosis. In mice transgenic for SV40T antigen, there was a five-fold increase in the thymidine labeling-index of glomerular tuft cells, which persisted even at late time points in severely sclerotic glomeruli, compared with a renewal rate of less than $1 \%$ in normal adult kidney. ${ }^{46}$ Our observations provide comparable evidence to support a role for E2F1 in both proliferative and sclerotic injury in progressive IgAN. Additional studies are required to determine whether such a role for E2F1 will prove to be a generic one in all human glomerulonephritides.

A potential weakness of our study is the inability to control for the effects of therapy on CCP expression. Although angiotensin II was reported to be capable of inducing proliferation and/or hypertrophy of cultured glomerular mesangial and endothelial cells in in vitro studies, ${ }^{47,48}$ and limited data suggest that treatment with ACE inhibitors may attenuate glomerular hypertrophy and abolish the glomerular expression of the CKI p16 ${ }^{\text {ink4 }}$ and p2 $7^{\text {kip } 1}$ in diabetic nephropathy of rat models, ${ }^{49}$ there is no substantial evidence that therapeutic drugs (ACEIs, AT1B, and/or immunosuppressive drugs) affect the expression of CCPs in resident glomerular cells, including glomerular epithelial and endothelial cells in human IgAN.

In summary, we have shown that the onset and magnitude of mesangial cell proliferation and glomerulosclerosis are associated with the upregulation of E2F1 by mesangial cells and the 
downregulation of $\mathrm{p} 27^{\mathrm{kip} 1}$ and $\mathrm{p} 57^{\mathrm{kip} 2}$ by GECs in human IgAN. We suggest the existence of coordinated regulation of proliferation and apoptosis in progressive glomerular injury; perturbation of this balance may lead to the irreversible damage characteristic of end-stage IgAN. Uncontrolled mesangial and endothelial cell proliferation, the transdifferentiation or dysregulated proliferation of GECs, and unnecessary apoptosis could contribute to progressive glomerulerosclerosis. Finally, we propose that E2F1 may serve as an independent marker for predicting the grade of mesangial hypercellularity and be considered as a key therapeutic target to inhibit the proliferative and sclerotic glomerular damage characteristic of progressive IgAN.

\section{Acknowledgements}

We are grateful to $\mathrm{Mr}$ Tan Tee Chock (Special Histopathological Laboratory, National University Hospital, Singapore), for his technical assistance in the preparation of light microscopic images. This work was supported by the Academic Research Fund Grant R-172-000-109-112 to RS and SI-HH.

\section{References}

1 Shankland SJ. Cell cycle regulatory proteins in glomerular disease. Kidney Int 1999;56:1208-1215.

2 Shankland SJ, Wolf G. Cell cycle regulatory proteins in renal disease: role in hypertrophy, proliferation, and apoptosis. Am J Physiol Renal Physiol 2000;278: F515-F529.

3 Shankland SJ, Hugo C, Coats SR, et al. Changes in cellcycle protein expression during experimental mesangial proliferative glomerulonephritis. Kidney Int 1996; 50:1230-1239.

4 Terada Y, Inoshita S, Nakashima O, et al. Cyclins and the cyclin-kinase system-their potential roles in nephrology. Nephrol Dial Transplant 1998;13: 1913-1916.

5 Schocklmann HO, Lang S, Sterzel RB. Regulation of mesangial cell proliferation. Kidney Int 1999;56: 1199-1207.

6 Pippin JW, Qu Q, Meijer L, et al. Direct in vivo inhibition of the nuclear cell cycle cascade in experimental mesangial proliferative glomerulonephritis with roscovitine, a novel cyclin-dependent kinase antagonist. J Clin Invest 1997;100:2512-2520.

7 Shankland SJ, Floege J, Thomas SE, et al. Cyclin kinase inhibitors are increased during experimental membranous nephropathy: potential role in limiting glomerular epithelial cell proliferation in vivo. Kidney Int 1997;52:404-413.

8 Schoecklmann HO, Rupprecht HD, Zauner I, et al. TGF-beta1-induced cell cycle arrest in renal mesangial cells involves inhibition of cyclin E-cdk 2 activation and retinoblastoma protein phosphorylation. Kidney Int 1997;51:1228-1236.

9 Shankland SJ, Pippin J, Flanagan M, et al. Mesangial cell proliferation mediated by PDGF and bFGF is determined by levels of the cyclin kinase inhibitor p27Kip1. Kidney Int 1997;51:1088-1099.

10 Shankland SJ, Scholey JW, Ly H, et al. Expression of transforming growth factor-beta 1 during diabetic renal hypertrophy. Kidney Int 1994;46:430-442.

11 Berger J. IgA glomerular deposits in renal disease. Transplant Proc 1969;1:939-944.

12 Ibels LS, Gyory AZ. IgA nephropathy: analysis of the natural history, important factors in the progression of renal disease, and a review of the literature. Medicine (Baltimore) 1994;73:79-102.

13 Radford Jr MG, Donadio Jr JV, Bergstralh EJ, et al. Predicting renal outcome in IgA nephropathy. J Am Soc Nephrol 1997;8:199-207.

14 Sinniah R, Javier AR, Ku G. The pathology of mesangial IgA nephritis with clinical correlation. Histopathology 1981;5:469-490.

15 Sinniah R, Pwee HS, Lim CH. Glomerular lesions in asymptomatic microscopic hematuria discovered on routine medical examination. Clin Nephrol 1976;5: 216-228.

16 Qiu LQ, Sinniah R, Hsu I-Hong. Downregulation of Bcl-2 by podocytes is associated with progressive glomerular injury and clinical indices of poor renal prognosis in human IgA nephropathy. J Am Soc Nephrol 2004;15:79-90.

17 Rui-Mei L, Kara AU, Sinniah R. In situ analysis of adhesion molecule expression in kidneys infected with murine malaria. J Pathol 1998;185:219-225.

18 Khan TN, Sinniah R. Renal tubular antiproteinase (alpha-1-antitrypsin and alpha-1-antichymotrypsin) response in tubulo-interstitial damage. Nephron 1993;65:232-239.

19 Sinniah R, Churg J. Effect of IgA deposits on the glomerular mesangium in Berger's disease. Ultrastruct Pathol 1983;4:9-22.

20 To KF, Choi PC, Szeto CC, et al. Outcome of IgA nephropathy in adults graded by chronic histological lesions. Am J Kidney Dis 2000;35:392-400.

21 Soma J, Saito T, Seino J, et al. Participation of CR1 (CD35), CR3 (CD11b/CD18) and CR4 (CD11c/CD18) in membranoproliferative glomerulonephritis type I. Clin Exp Immunol 1995;100:269-276.

22 Hotta O, Furuta T, Chiba S, et al. Regression of IgA nephropathy: a repeat biopsy study. Am J Kidney Dis 2002;39:493-502.

23 Nakopoulou L, Stefanaki K, Salpigidis K, et al. The value of proliferating cell nuclear antigen (PCNA)/ cyclin in the assessment of cell proliferation in glomerulonephritis. Histol Histopathol 1997;12: 655-662.

24 Yoshioka K, Takemura T, Akano N, et al. Cellular and non-cellular compositions of crescents in human glomerulonephritis. Kidney Int 1987;32:284-291.

25 Nagata M, Shu Y, Tomari S. Role of cell cycle molecules in the pathophysiology of glomerular epithelial cells. Microsc Res Techn 2002;57: 203-207.

26 Mundle SD, Saberwal G. Evolving intricacies and implications of E2F1 regulation. FASEB J 2003;17: 569-574.

27 Inoshita S, Terada Y, Nakashima O, et al. Regulation of the G1/S transition phase in mesangial cells by E2F1. Kidney Int 1999;56:1238-1241.

28 Ren B, Cam H, Takahashi Y, et al. E2F integrates cell cycle progression with DNA repair, replication, and G(2)/M checkpoints. Genes Dev 2002;16:245-256. 
29 Muller H, Bracken AP, Vernell R, et al. E2Fs regulate the expression of genes involved in differentiation, development, proliferation, and apoptosis. Genes Dev 2001;15:267-285.

30 Inoshita S, Terada Y, Nakashima O, et al. Roles of E2F1 in mesangial cell proliferation in vitro. Kidney Int 1999;56:2085-2095.

31 Maeshima Y, Kashihara N, Yasuda T, et al. Inhibition of mesangial cell proliferation by E2F decoy oligodeoxynucleotide in vitro and in vivo. J Clin Invest 1998;101:2589-2597.

32 Tomita N, Horiuchi M, Tomita S, et al. An oligonucleotide decoy for transcription factor E2F inhibits mesangial cell proliferation in vitro. Am J Physiol 1998;275:F278-F284.

33 Tsuboi N, Yoshida H, Kawamura $\mathrm{T}$, et al. Threedimensional matrix suppresses E2F-controlled gene expression in glomerular mesangial cells. Kidney Int 2000;57:1581-1589.

34 Fujigaki Y, Sun DF, Fujimoto T, et al. Cytokines and cell cycle regulation in the fibrous progression of crescent formation in antiglomerular basement membrane nephritis of WKY rats. Virchows Arch 2001; 439:35-45.

35 Pabst R, Sterzel RB. Cell renewal of glomerular cell types in normal rats. An autoradiographic analysis. Kidney Int 1983;24:626-631.

36 Barisoni L, Mokrzycki M, Sablay L, et al. Podocyte cell cycle regulation and proliferation in collapsing glomerulopathies. Kidney Int 2000;58:137-143.

37 Nagata M, Horita S, Shu Y, et al. Phenotypic characteristics and cyclin-dependent kinase inhibitors repression in hyperplastic epithelial pathology in idiopathic focal segmental glomerulosclerosis. Lab Invest 2000;80:869-880.

38 Wang S, Kim JH, Moon KC, et al. Cell-cycle mechanisms involved in podocyte proliferation in cellular lesion of focal segmental glomerulosclerosis. Am J Kidney Dis 2004;43:19-27.

39 Baker AJ, Mooney A, Hughes J, et al. Mesangial cell apoptosis: the major mechanism for resolution of glomerular hypercellularity in experimental mesangial proliferative nephritis. J Clin Invest 1994;94: 2105-2116.

40 Shimizu A, Masuda Y, Kitamura H, et al. Apoptosis in progressive crescentic glomerulonephritis. Lab Invest 1996;74:941-951.

41 Thomas GL, Yang B, Wagner BE, et al. Cellular apoptosis and proliferation in experimental renal fibrosis. Nephrol Dial Transplant 1998;13:2216-2226.

42 Tashiro K, Kodera S, Takahashi Y, et al. Detection of apoptotic cells in glomeruli of patients with IgA nephropathy. Nephron 1998;79:21-27.

43 Sugiyama H, Kashihara N, Makino H, et al. Apoptosis in glomerular sclerosis. Kidney Int 1996;49:103-111.

44 Haas CS, Schocklmann HO, Lang S, et al. Regulatory mechanism in glomerular mesangial cell proliferation. J Nephrol 1999;12:405-415.

45 Maeshima Y, Kashihara N, Sugiyama H, et al. Antisense oligonucleotides to proliferating cell nuclear antigen and Ki-67 inhibit human mesangial cell proliferation. J Am Soc Nephrol 1996;7:2219-2229.

46 Pesce CM, Striker LJ, Peten E, et al. Glomerulosclerosis at both early and late stages is associated with increased cell turnover in mice transgenic for growth hormone. Lab Invest 1991;65:601-605.

47 Wolf G, Ziyadeh FN, Zahner G, et al. Angiotensin II is mitogenic for cultured rat glomerular endothelial cells. Hypertension 1996;27:897-905.

48 Orth SR, Weinreich T, Bonisch S, et al. Angiotensin II induces hypertrophy and hyperplasia in adult human mesangial cells. Exp Nephrol 1995;3:23-33.

49 Wolf G. Cell cycle regulation in diabetic nephropathy. Kidney Int 2000;77:S59-S66. 